
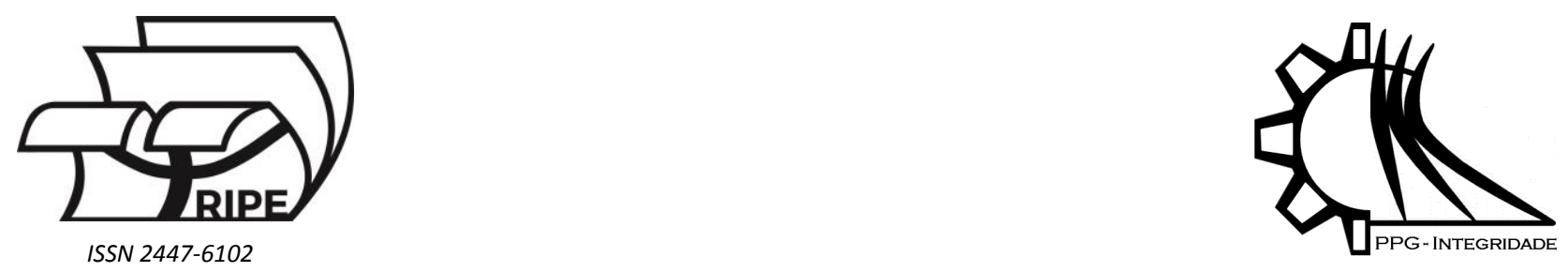

Article

\title{
Aplicação de simulação computacional para o aumento de eficiência energética de uma instalação frigorífica
}

\author{
Ivoni C. A. Jr'* , Danilo. B. de Aguiar², Sandro Germano ${ }^{3}$ \\ 1 IFRS - Campus Rio Grande; ivoni.acunha@riogrande.ifrs.edu.br \\ 2 Universidade Federal do Rio Grande - FURG; danilobarreto95@gmail.com \\ 3 Less Energy LTDA \\ * Correspondente: ivoni.acunha@riogrande.ifrs.edu.br; Tel.: +55 53981119128
}

Received: 14/12/2018; Accepted: 05/01/2019; Published: 16/01/2019

Resumo: Aspectos envolvendo a maximização da eficiência energética de uma instalação industrial é um tópico de grande importância, pois atualmente existem onerosas tarifas de energia elétrica e qualquer redução de consumo da mesma, resulta em grandes benefícios tanto para empresa como para a matriz energética do país, visto que unidades frigoríficas têm um grande consumo de eletricidade. Com isso, estas melhorias podem, em alguns casos, ser obtidas apenas através de modificações de condições operacionais da planta, que visam reduzir os desperdícios. Assim, este trabalho tem como objetivo apontar ações para melhoria da eficiência energética do sistema de refrigeração por $\mathrm{NH}_{3}$ de um armazém frigorífico, através do uso de modelagem matemática e simulações computacionais da planta frigorífica, utilizando o software EES (Engineering Equation Solver) como ferramenta para a modelagem matemática e realização das simulações computacionais. Além disso, o sistema de refrigeração possui motores elétricos tanto dos evaporadores como dos condensadores, acionados por inversores de frequência VSDs (Variable Speed Drive). Dessa forma, foram avaliadas diferentes condições de regime de temperaturas de operação e de valores de frequência dos VSDs, com objetivo de obter o menor consumo de energia elétrica, de modo a atender a uma condição específica de funcionamento da instalação industrial. Além disso, foi identificado que o sistema de refrigeração possui contaminação por água, que impacta no consumo de energia elétrica. $O$ estudo realizado demonstrou que sem realizar nenhuma modificação estrutural na planta frigorífica, é possível reduzir em 9,3\% o consumo de energia elétrica.

Palavras-chaves: Eficiência energética, simulação computacional, variadores de velocidade, refrigeração industrial.

\section{Computational simulation employment to energetic efficiency improvement at a refrigeration system}

\begin{abstract}
Aspects in relationship to the maximization of energy efficiency in industrial installation is a topic of high importance, due to actually exists onerous tariffs of electric energy and any reduction of consumption of this, result in great improvements not just for the industry, but also to the energetic matrix of the country, since large refrigeration units have a high electrical energy consumption. Moreover, with these improvements, in some cases, can be possible achieve through changes in operations conditions, reduction in the consumption of electrical energy. Thereby, this study has the objective to point action to improve the energy efficiency of a refrigeration system that uses $\mathrm{NH}_{3}$ of a refrigerated warehouse, through the use o mathematical modeling and computational simulation of the system in analyze, utilizing the software EES (Engineering Equation Solver) as a tool to mathematical modeling and do the computational simulations. Furthermore, the electrical motors of the evaporators and condensers are drive with VSDs (variable speed drives). Thus, were evaluated different conditions of regime temperature operation and values of frequency of the VSDs, with aim of obtain the smallest electrical energy consumption, in order to meet the specific conditions of running of the installation. It was identified that the refrigeration system has some water
\end{abstract}


contamination that also impact the consumption of electrical energy. This study demonstrated that without realize none structural modification the refrigeration system, is possible reduce in $9,3 \%$ the consumption of electric energy.

Keywords: Energy efficiency, computational simulation, variable speed drives, industry refrigeration.

\section{Introdução}

Atualmente as onerosas tarifas relativas à energia elétrica praticadas no Brasil têm motivado estudos que conduzem a melhores práticas nos mais diversos ramos produtivos a fim de reduzir os custos operacionais, melhorar a competitividade no mercado e reduzir os custos do consumidor final. Não menos importante, existem grandes impactos ambientais produzidos pelo expressivo aumento do consumo de demanda de eletricidade, que também comprometem a capacidade da matriz energética brasileira

Os principais elementos agravantes do consumo energético geralmente estão ligados à manutenção, operação e à correta seleção dos equipamentos. Obter o melhor de uma instalação de refrigeração é uma tarefa bastante difícil, cujas práticas utilizadas muitas vezes são baseadas na tentativa e erro ou na experiência profissional de técnicos e engenheiros.

Neste sentido, a utilização mais racional de insumos energéticos promovida pela implementação de parâmetros obtidos através de simulação computacional de cada planta pode ser uma grande aliada. Desta metodologia, resultam menores desperdícios e maiores ganhos energéticos, podendo-se predizer o comportamento de um grande sistema e/ou instalação de equipamentos para experimentação.

Assim, este trabalho tem como objetivo apontar ações para promover a melhoria da eficiência energética do sistema de refrigeração industrial de um armazém frigorífico, através do uso de modelagem matemática e simulações computacionais da planta frigorífica, utilizando o software EES (Engineering Equation Solver) como ferramenta para a modelagem matemática e realização das simulações. Além disso, o sistema de refrigeração possui motores elétricos tanto dos evaporadores como dos condensadores, acionados por inversores de frequência VSDs (Variable Speed Drive). Dessa forma, foram avaliadas diferentes condições de regime de temperaturas de operação e de valores de frenquência dos VSDs, com objetivo de obter o menor consumo de eletricidade, de modo a atender a uma condição específica de funcionamento da instalação industrial.

\section{Referencial teórico}

Várias técnicas têm sido usadas para controle de capacidade, mas o variador de velocidade foi mostrado ser a tecnologia mais eficaz e flexível em comparação com outras técnicas, como by-pass de gás quente, controle de temperatura do evaporador baseado em uma válvula de expansão eletrônica, controle de compressores e carregamento de cilindros (QURESHI; TASSOU, 1996).

O compressor é o componente que mais consome energia do sistema de refrigeração, a ponto de afetar significativamente o custo de operação da instalação. Para isso é indispensável o conhecimento dos regimes de compressão, plano de manutenção, seleção adequada de cada equipamento no momento do projeto, afim de que estejam bem dimensionados para assegurar o bom funcionamento e garantir a melhor eficiência (STOECKER; JABARDO, 2002).

$\mathrm{Na}$ África do Sul existem enormes sistemas de resfriamento de minas, que se caracterizam por serem identificados como grandes consumidores de eletricidade, (PLESSIS et al., 2013) desenvolveram um estudo de implementação piloto em uma mina, onde é demonstrado que o uso em grande escala de VSDs (variable speed drive) em bombas e ventiladores de sistemas de arrefecimento de minas é economicamente viável e pode alcançar uma economia anual de energia elétrica total de $144721 \mathrm{MWh}$, ou 32.2\%. Ademais, é possível uma economia de custo anual de US $\$ 6938148$ e redução de emissões de $\mathrm{CO}_{2}$ de 132 Mton. A implementação de VSDs em compressores de resfriamento de mina também resultará em grandes economias de energia, mas não é economicamente viável no momento. Os resultados do estudo piloto indicam uma economia de eletricidade de $29.9 \%$.

(YU; CHAN, 2006) constataram que o uso de ventiladores com velocidade variável no condensador, aliado com o controle da temperatura de condensação e usados em conjunto nos chillers parafuros refrigeradores a ar, permite que operem com mais eficiência, podendo reduzir seu consumo anual de eletricidade normalizado pela área total do piso do edifício de $56,2 \mathrm{kWh} / \mathrm{m}^{2}$ para $44 \mathrm{kWh} / \mathrm{m}^{2}$.

Na temporada de verão de Kuwait, visando saber qual seria o efeito da instalação de inversores de frequência variável em ventiladores de torres de resfriamentos em relação ao sistema de dupla velocidade, foi constatado que o 
sistema com tecnologia de velocidade variável é uma solução tanto para redução de $12 \%$ no consumo na água, quanto na economia de energia, onde a potência consumida combinada dos chillers e ventiladores das torres de resfriamentos foram reduzidos em 5.8\% (AL-BASSAM; ALASSERI, 2013).

Ambos os modos de funcionamento, tanto o compressor, quanto os ventiladores, eles devem trabalhar na frequência máxima para alcançar as capacidades máximas de aquecimento e resfriamento. Em contrapartida, para o consumo de energia mais baixo, a frequência do compressor e as frequências dos ventiladores do evaporador devem ser mínimas, enquanto as frequências dos ventiladores do condensador devem ser diferentes de acordo com o modo de operação. Por exemplo, no modo de aquecimento, a melhor frequência do ventilador do condensador muda de acordo com a condição de trabalho, onde aumenta com a temperatura exterior crescente. Contudo, no arrefecimento as frequências melhores do ventilador do condensador deve ser basicamente o mesmo em $35 \mathrm{~Hz}$ apesar das diferentes condições de trabalho (PENG; DU, 2015).

A lei dos ventiladores quando aplicada demonstra que a velocidade variável é um meio eficaz de controlar o desempenho de um ventilador, pois quando alterado a velocidade de rotação do ventilador pode controlar diretamente o volume e a pressão do fluido deslocado (MOBLEY, 2011).

Em sistemas de refrigeração o evaporador é o equipamento indispensável para produção do frio. 0 evaporador é o agente direto de resfriamento, constituindo uma interface entre o processo e o circuito frigorífico. Assim, tem como função ser o equipamento que evaporara o fluido refrigerante através da extração de calor do ambiente a ser refrigerado por meio do fenômeno transferência de calor (STOECKER; JABARDO, 2002). Esse fenômeno chamado transferência de calor acontece em todos os trocadores de calor e ocorre do fluido refrigerante entre $o$ ar, água ou outro fluido e depende da magnitude da diferença de temperatura (ÇENGEL; GHAJAR, 2012).

Como pode ser observado, muitas análises e estudos contemplando instalações de refrigeração têm sido feitas. Entretanto, poucas são as situações em que são avaliadas plantas frigoríficas que operam com $\mathrm{NH}_{3}$ como fluido refrigerante.

\section{Modelagem matemática}

\subsection{Evaporadores}

A eficiência da superfície externa $\eta_{e}$ de uma superfície aletada, é avaliada em função das áreas da superfície aletada $A_{f}$, da área da superfície total externa $A_{e}$, e da eficiência $\eta_{a}$ das aletas pela seguinte Eq. (1) (MCQUISTON, 1994).

$$
\eta_{e}=1-\frac{A_{f}}{A_{e}}\left(1-\eta_{a}\right)
$$

A avaliação da eficiência das aletas depende da forma como estas são colocadas nos tubos do trocador de calor. Por analogia com um conjunto elétrico, constituído por resistências em série, para trocadores de calor de tubos lisos, a Eq. (2) expressa a resistência térmica total $R_{\text {total }}$ em função das resistências térmicas do tubo $R_{\text {tubo, }}$ de contato $R_{\text {cont }}$, de incrustações $R_{\text {incrust }}$, do óleo presente no interior dos tubos $R_{\text {óleo, }}$ do gelo formado na superfície $R_{\text {gelo }}$ da eficiência da superfície externa $\eta_{e}$, dos coeficientes de transmissão de calor interno $h_{i}$ e externo $h_{e}$ e das áreas externas $A_{e}$ e interna $A_{i}$ de troca de calor

$$
R_{\text {total }}=\frac{1}{h_{i} A_{i}}+R_{\text {tubo }}+R_{\text {cont }}+R_{\text {incrust }}+R_{\text {óleo }}+R_{\text {gelo }}+\frac{1}{\eta_{e} h_{e} A_{e}}
$$

O coeficiente global de transferência de calor externo é dado pela Eq. (3).

$$
\frac{1}{U_{e} A_{e}}=\frac{1}{h_{e} A_{e}}+R_{\text {tubo }}+R_{\text {cont }}+R_{\text {incrust }}+R_{\text {óleo }}+R_{\text {gelo }}+\frac{1}{\eta_{e} h_{e} A_{e}}
$$

Neste trabalho, para a região de evaporação, será considerado um processo psicrométrico com resfriamento e desumidificação do ar e a serpentina nesta área do evaporador se apresentará congelada.

Se considerarmos o efeito da resistência de contato das aletas, da presença de óleo, da contaminação do refrigerante, das incrustações, da presença de gelo e eficiência da aleta como uma resistência equivalente $\left(h_{e q}\right)$ podemos obter a equação para o $U$ representado pela Eq. (4), através da simplificação da Eq. (3). 


$$
U=\frac{1}{\frac{d_{\text {ext }}}{d_{\text {int }}}\left(\frac{1}{h_{\text {int }}}\right)+\frac{d_{\text {ext }}}{d_{\text {int }}}\left(\frac{L}{K_{T}}\right)+\frac{1}{h_{\text {eq }}}}
$$

Onde $K_{t}$ é a condutividade térmica do tubo $\left(\mathrm{Wm}^{-1} \mathrm{~K}^{-1}\right), d_{\text {int }}$ e $d_{\text {ext }}$ são, respectivamente, os diâmetros interno e externo do tubo $(\mathrm{m}), d_{m}$ é o diâmetro médio do tubo dado pela média aritmética de $d_{\text {int }}$ e $d_{\text {ext }}, L$ é a espessura do tubo $(\mathrm{m}), h_{\text {int }}$ é o coeficiente de transferência de calor entre o fluido refrigerante e a superfície interna do tubo (W $\mathrm{m}^{-2}{ }^{\circ} \mathrm{C}^{-1}$ ) e $h_{e q}$ pode ser obtido através de medições experimentais e balanços térmicos, uma vez que a capacidade $\dot{q}$ do sistema pode ser determinada resolvendo-se a Eq. (5).

$$
U A=\int U d A_{h} \frac{d \dot{q}}{\Delta T_{l m}}
$$

Sendo $\Delta T_{l m}$ a média logarítmica de temperatura entre as correntes de ar e de Amônia.

\subsection{Compressores}

A taxa de transferência nos evaporadores deve ser compatível com aquela desempenhada pelos compressores. Estes por sua vez, podem ter sua capacidade avaliada empregando-se a modelagem matemática, de acordo com a Eq. (6), obtida pelo mesmo procedimento utilizado por (ACUNHA et al., 2011).

$$
\dot{q}=\mathrm{C} 1+\mathrm{C} 2\left(T_{s}\right)+\mathrm{C} 3\left(T_{c}\right)+\mathrm{C} 4\left(T_{s}^{2}\right)+\mathrm{C} 5\left(T_{s} T_{c}\right)+\mathrm{C} 6\left(T_{c}^{2}\right)+\mathrm{C} 7\left(T_{s}^{3}\right)+\mathrm{C} 8\left(T_{c} T_{s}^{2}\right)+\mathrm{C} 9 \cdot\left(T_{s} T_{c}^{2}\right)+\mathrm{C} 10 \cdot\left(T_{c}^{3}\right)
$$

Onde $T_{S}$ e $T_{C}$ são as temperaturas de evaporação e condensação do fluido refrigerante, respectivamente $\left({ }^{\circ} \mathrm{C}\right)$.

Assim, a Eq. (6) deve expressar a capacidade frigorífica do compressor em função das temperaturas correspondentes ao regime operacional e seus coeficientes devem ser determinados através de dados fornecidos pelos fabricantes do equipamento ou experimentalmente.

\subsection{Condensadores}

A determinação de coeficientes de transferência de calor médios para fluidos sob condensação também pode ser empregada. (BEJAN, 1996) apresenta várias correlações para determinação do coeficiente de transferência de calor para fluidos condensando pelos lados interno e externo dos tubos, dentre estas, a correlação de (CHATO, 1962 apud BEJAN, 1996), para condensação interna em tubos horizontais dominada pela convecção natural, para baixos números de Reynolds do vapor ( $\operatorname{Re}<3,5 \times 104)$ representada pela Eq. (7)

$$
h_{i}=0,55\left[\frac{\rho_{L}\left(\rho_{L}-\rho_{V}\right) g h_{f g}^{\prime} k_{L}^{3}}{\mu_{L} d\left(T_{s a t}-T_{p}\right)}\right]^{1 / 4}
$$

Onde $h_{f g}^{\prime}$ é o calor latente de vaporização corrigido $(\mathrm{j} / \mathrm{kg})$ que visa incluir o efeito do calor sensível devido à redução de temperatura do líquido condensado abaixo da temperatura de saturação em regiões próximas a parede. Assim, $h_{f g}^{\prime}$ é dado pela Eq. (8).

$$
h_{f g}^{\prime}=h_{f g}+\frac{3}{8} C_{p, L}\left(T_{s a t}-T_{p}\right)
$$

Nesta equação, $C_{p, L}$ é o calor específico do líquido $\left(\mathrm{J} \mathrm{Kg}^{-1} \mathrm{~K}^{-1}\right)$.

A Eq. (9), auxilia na determinação do coeficiente global de transferência de calor definido para o lado externo dos tubos (ASHRAE, 2000) 


$$
U=\frac{1}{\frac{d_{\text {ext }}}{d_{\text {int }}}\left(\frac{1}{h_{\text {int }}}\right)+\frac{d_{\text {ext }}}{d_{\text {int }}}\left(\frac{L}{K_{T}}\right)+\frac{1}{h_{\text {ext }}}}
$$

onde $h_{\text {ext }}$ é o coeficiente de transferência de calor entre a superfície externa dos tubos e a água $\left(\mathrm{W} \mathrm{m}^{-2}{ }^{\circ} \mathrm{C}^{-1}\right)$.

O coeficiente de transferência de calor entre o tubo e a água foi objeto de estudo de alguns pesquisadores que encontraram correlações baseadas na relação $\left(\Gamma / \mathrm{d}_{\text {ext }}\right)$, em que $\Gamma$ representa a vazão de água por unidade de comprimento de tubo $\left(\mathrm{kg} \mathrm{m}^{-1} \mathrm{~s}^{-1}\right)$.

A correlação de (PARKER; TREYBAL, 1961), foi obtida em cinco situações distintas, sendo que para o caso de condensadores evaporativos, a correlação encontrada foi à Eq. (10):

$$
h_{e}=704\left(1,39+0,022 T_{w}\right)\left(\frac{\Gamma}{d_{\text {ext }}}\right)^{1 / 3}
$$

onde $T_{w}$ é a temperatura da água.

Após a determinação dos coeficientes de transferência de calor dos lados interno e externo dos tubos pode-se determinar o coeficiente global de transferência de calor, Eq. (11), que pode ser utilizado na determinação da capacidade do condensador evaporativo.

$$
\dot{q}=U A \Delta T
$$

onde $A$ é a área de troca térmica $\left(\mathrm{m}^{2}\right)$ e $\Delta T$ é a diferença de temperatura entre o fluido refrigerante e a água $\left({ }^{\circ} \mathrm{C}\right)$.

A taxa de transferência de calor também pode ser determinada através de medições experimentais, medindo-se a vazão de ar e as condições do ar na entrada e na saída do condensador, empregando-se os valores medidos na seguinte Eq. (12).

$$
\dot{q}=\dot{m}_{a r}\left(i_{a r, s a i}-i_{a r, e n t}\right)-\dot{m}_{w r} i_{w r}
$$

onde $\dot{m}_{a r}$ é a vazão mássica de ar seco que passa através do condensador, em $\mathrm{kg} \mathrm{s}^{-1}$, e $i_{a r, s a i}$ e $i_{a r, e n t}$ são, respectivamente, a entalpia de saída e entrada do ar, em kJ kg-1, $\dot{m}_{w r}$ é a vazão mássica da água de reposição, em kg $\mathrm{s}^{-1}$ e $i_{w}$ é a entalpia da água na bacia, em kJ kg-1.

\section{Objeto de estudo}

Trata-se aqui de um estudo feito em uma empresa de estocagem de alimentos, onde foram coletados dados em campo pertinentes à operação de uma instalação de refrigeração que opera para manter o funcionamento de uma antecâmara, um túnel de recuperação quatro câmaras de estocagem.

A relação dos equipamentos inclui:

- 12 evaporadores nas antecâmaras com 3 motores de ventilador de 0,7 kW cada evaporador;

- 6 evaporadores em cada câmara de estocagem com 3 motores de ventilador de $4 \mathrm{~kW}$ em cada evaporador;

- 2 evaporadores com 2 motores de ventilador de 7,5 cv em cada evaporador;

- 1 condensador evaporativo com 18 motores de 2,4 cv e duas bombas d'água de $5 \mathrm{cv}$;

- 1 condensador evaporativo com 18 motores de 3,0 cv e duas bombas d'água de $5 \mathrm{cv}$;

- 2 bombas de amônia de $5 \mathrm{cv}$ e $10 \mathrm{cv}$, respectivamente;

- 2 compressores tipo parafuso com motor de $500 \mathrm{cv}$ em cada compressor;

- 1 compressor tipo parafuso com motor de $400 \mathrm{cv}$.

\section{Metodologia}

Com base nos dados medidos foi feita a modelagem matemática de todo o sistema a fim de propiciar a simulação computacional dos principais equipamentos consumidores de eletricidade operando em conjunto. $A$ situação que foi verificada é diferente daquela provavelmente prevista na do projeto inicial, devido à necessidade atual da empresa.

As grandezas mais relevantes que foram tomadas como base para executar a análise do sistema foram: tempo de operação, carga térmica, temperatura das câmaras e antecâmaras, pressões de trabalho, potência e energia elétrica consumidas, custo mensal com estimativa de 22 dias trabalhados. 
Durante a tomada de dados verificou-se uma operação com carga reduzida, onde apenas as câmaras 1,2 e 3 encontravam-se em funcionamento. Verificou-se também, que o tempo de operação diária da sala de máquinas é de aproximadamente 8 horas, acarretando em uma variação significativa na temperatura das câmaras, as quais atingem, por vezes a temperaturas próximas de $0^{\circ} \mathrm{C}$. Esta análise baseia-se em um dia de operação em que a temperatura máxima das câmaras foi de $-8^{\circ} \mathrm{C}$ e a mínima de aproximadamente $-23,1^{\circ} \mathrm{C}$ com a operação iniciando por volta das $4 \mathrm{~h}$ e encerrando às $12 \mathrm{~h}$. A avaliação em campo mostrou uma tendência de que nos primeiros 20 minutos as câmaras têm sua temperatura reduzida de $-8^{\circ} \mathrm{C}$ até $-13^{\circ} \mathrm{C}$, aproximadamente. De $-13^{\circ} \mathrm{C}$ à $-20^{\circ} \mathrm{C}$ o tempo de operação necessário é de 75 minutos. Com mais $100 \mathrm{~min}$ de operação as câmaras alcançam a temperatura de $-23,1^{\circ} \mathrm{C}$. $\mathrm{O}$ tempo total, aproximado, para redução até esta temperatura desde o início do funcionamento da sala de máquinas é de aproximadamente $3 \mathrm{~h} 15 \mathrm{~min}$. Assim, o sistema encontra-se em regime transiente durante $40 \%$ do tempo de funcionamento total. No tempo restante (aproximadamente 60\%) a condição já é estável com relação à temperatura das câmaras. Tendo em vista o regime transiente de temperaturas, considerou-se uma temperatura média para cada tempo de variação. A Fig. 1 apresenta uma tela do programa construído para a simulação do sistema considerando a condição de regime permanente verificada em um dos dias em que foram realizadas as medições. 0 gráfico apresentado na Fig. 2 mostra a evolução da temperatura das câmaras e o consumo energético (em kWh) durante as 8 horas de operação neste dia.
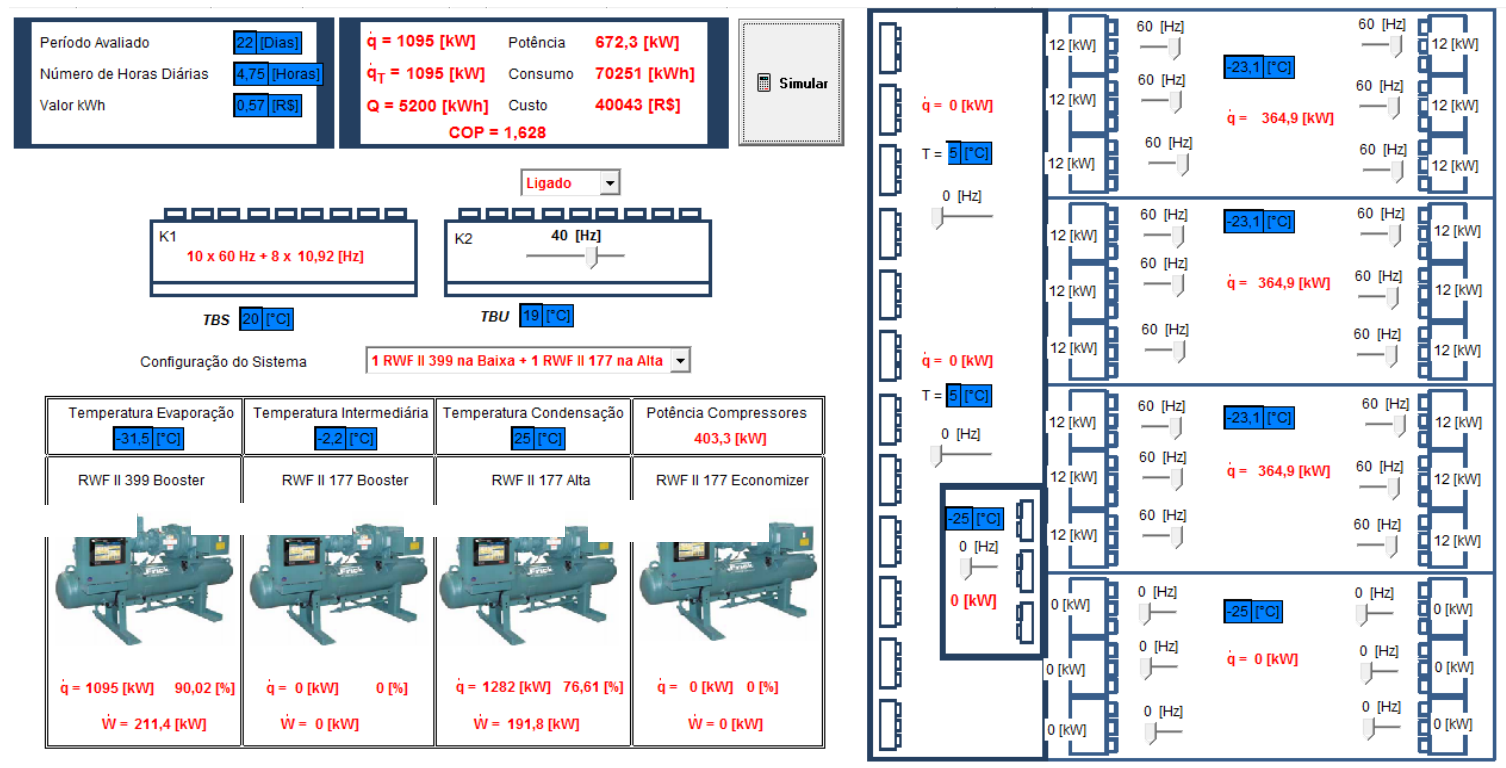

Figura 1. Operação em regime permanente com as câmaras estabilizadas em $-23,1^{\circ} \mathrm{C}$

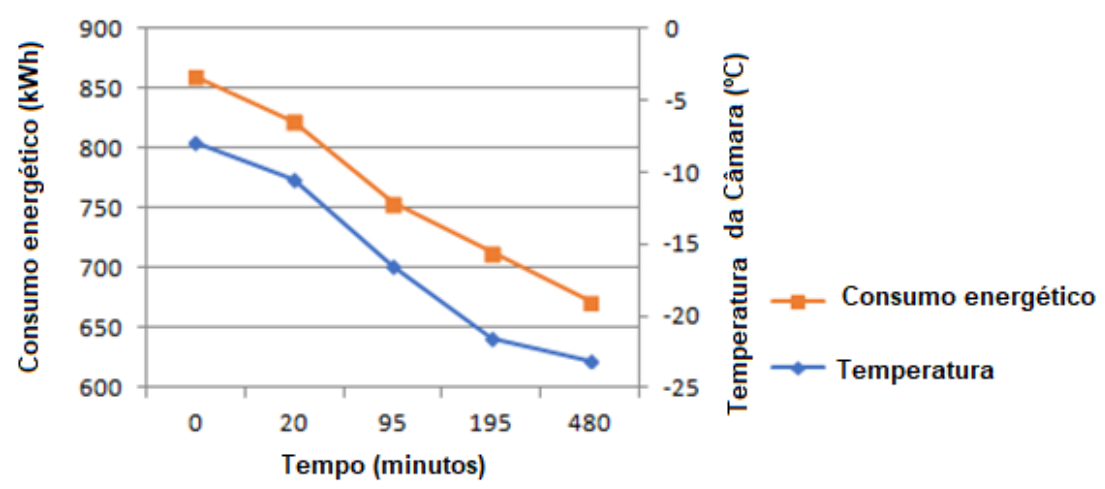

Figura 2. Evolução da temperatura das câmaras e potência consumida 
A Fig. 3 mostra o consumo de energia em cada período operacional anteriormente citado, bem como o consumo total do sistema frigorífico em neste dia analisado através da simulação computacional, conforme apresentado na Fig. 1.

\section{Consumo em kWh}

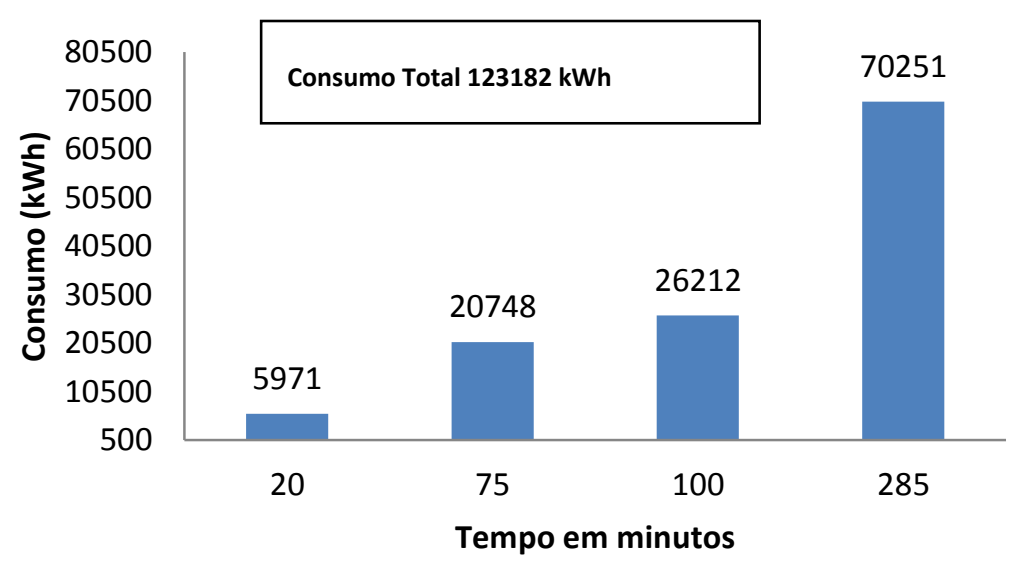

Figura 3. Consumo de energia

\section{Contaminação por água}

Em instalações de refrigeração frequentemente é encontrada uma considerável quantidade de água juntamente com o fluido refrigerante.

A contaminação por água pode provocar efeitos indesejáveis nos sistemas frigoríficos tais como diminuição da capacidade de refrigeração e do coeficiente de performance (COP), corrosão galvânica em válvulas e linhas e, o aumento do consumo de óleo e deterioração de componentes devido à corrosão.

De forma a manter boas condições operacionais, o percentual de água deve ser inferior a $0.5 \%$, sendo que o grau de pureza da amônia recomendada para sistemas de refrigeração é de $99.95 \%$, ou seja, no máximo $0.05 \%$ de água.

Nesta instalação frigorífica foi encontrada uma quantidade de água igual a $2.8 \%$ o que acarreta em uma redução de capacidade da instalação frigorífica.

Com a eliminação da água presente no sistema, o consumo energético mensal poderia ser reduzido de 123182 kWh para 118596 kWh. Percebe-se, então que o desperdício mensal de energia é de aproximadamente 4586 kWh, com o sistema operando apenas durante 8 horas diárias. Ao longo de 1 ano este valor chega a aproximadamente 55032 kWh.

\section{Resultados e discussões}

Considerando as antecâmaras ligadas, a carga térmica das câmaras de estocagem reduzirá, e o sistema se tornará mais eficiente. Outra ação que pode ser significativa é modificar a temperatura de evaporação para $-29^{\circ} \mathrm{C}$ mantendo as mesmas temperaturas nas câmaras de estocagem para viabilizar a carga térmica necessária.

Ainda dentro desta análise, outra possibilidade de ganho está associada aos condensadores evaporativos, uma vez que estes têm seu funcionamento relacionado com a temperatura de condensação. Os 2 condensadores mantêm a rotação dos ventiladores de forma que a temperatura de condensação permaneça em torno de $25^{\circ} \mathrm{C}$. Tem-se, entretanto, um dos condensadores com todos os motores de 2,4 cv acionados por inversor de frequência, enquanto que o outro possui motores de 3,0 cv e apenas 10 destes podem ter sua frequência de acionamento modificada.

Assim, foram feitos dois tipos de simulação: primeira delas utilizando apenas um dos condensadores; e a segunda com os dois condensadores funcionando a fim de encontrar a melhor frequência para os condensadores, ou seja, aquelas que resultam no menor consumo energético para toda a instalação frigorífica;

O gráfico da Fig. 4a, mostra o consumo do sistema frigorífico quando apenas o condensador $\mathrm{K} 1$ está em operação. Nesta condição a frequência de acionamento que resulta no menor consumo energético é 35,5 Hz com uma temperatura de condensação de $26,5^{\circ} \mathrm{C}$. Com isso, o consumo energético passa a ser de $63649 \mathrm{kWh}$. Entretanto, o consumo é superior ao da condição em que os 2 condensadores estão operando, conforme pode ser observado na 
Fig. 4b. A melhor condição operacional é observada quando o acionamento de $\mathrm{K} 2$ se dá a $28 \mathrm{~Hz}$, pois resultará em um consumo mínimo de 63222 kWh.
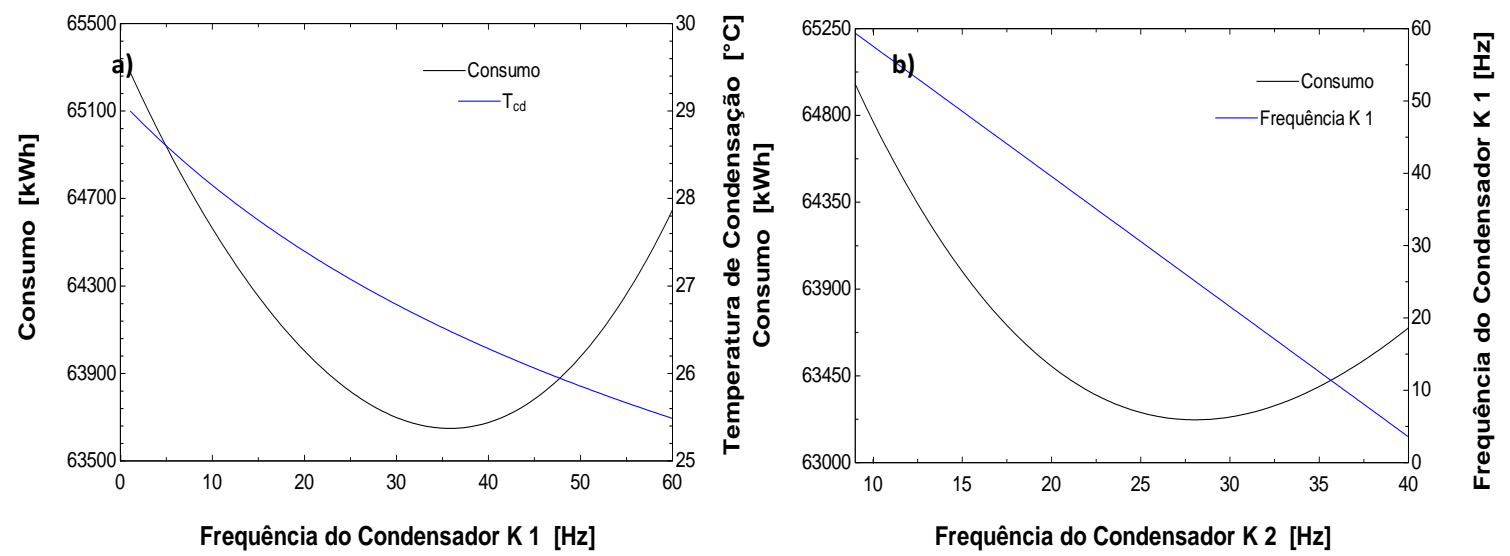

Figura 4. Operação dos condensadores em configurações diferentes

Assim, a melhor alternativa é manter os 2 condensadores ligados com as antecâmaras em funcionamento com os ventiladores em frequência reduzida. Outra recomendação é modificar a temperatura intermediária de $0^{\circ} \mathrm{C}$ para $-2,2^{\circ} \mathrm{C}$.

Destaca-se ainda, que a melhor forma de operação se dará com a implementação de um sistema com temperatura de condensação flutuante, haja vista as grandes variações de carga térmica e climáticas experimentadas pelo sistema de refrigeração.

Efetuando-se a mesma análise para o regime transiente também, percebe-se uma redução no consumo energético conforme pode ser verificado no gráfico da Fig. 5. Em todas as situações operacionais o consumo é menor na nova condição operacional. O total de energia que seria economizada nesta condição totalizaria 11415 kWh o que corresponde a aproximadamente $9.3 \%$.

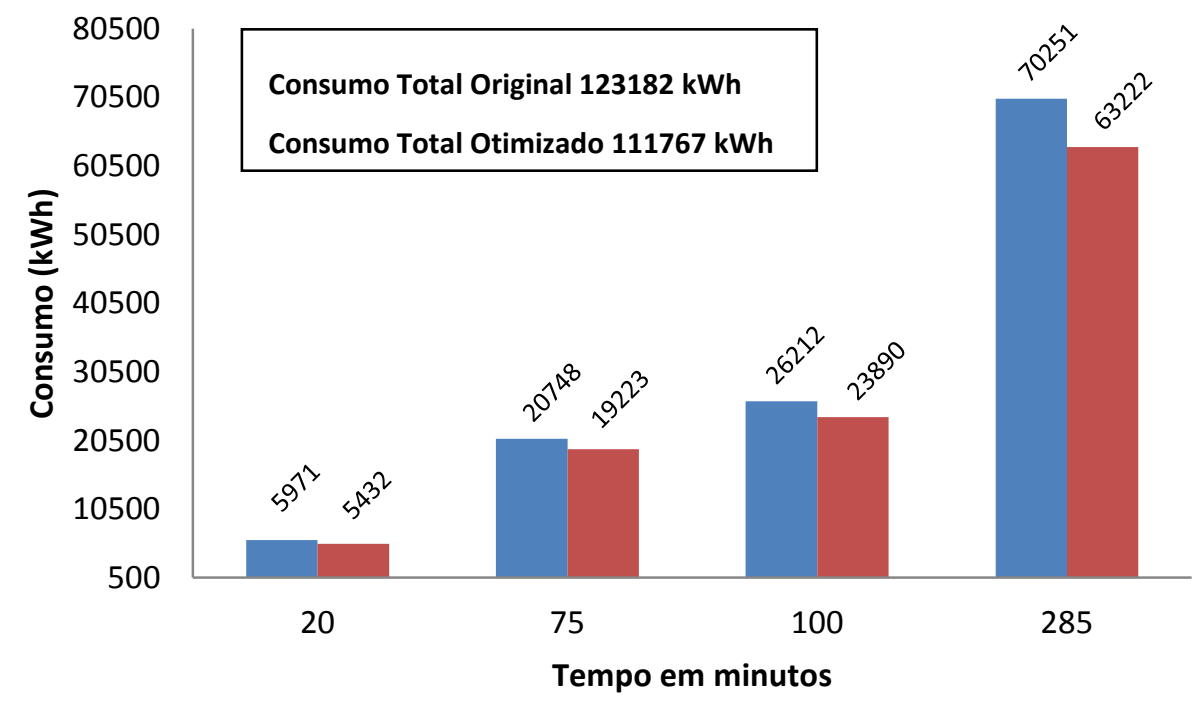

Figura 5. comparativo energético

\section{Conclusões}

Com base no exposto percebe-se claramente que melhores condições operacionais podem ser determinadas através da simulação computacional da instalação, culminando na obtenção de menores valores de consumo energético. 
O resultado das simulações feitas mostra um total de energia que pode ser economizada totalizaria $11415 \mathrm{kWh}$ o que corresponde a aproximadamente $9.3 \%$, sem qualquer modificação estrutural na instalação frigorífica.

A eliminação da contaminação por água no sistema poderá propiciar uma redução no consumo energético da planta frigorífica podendo chegar a $16001 \mathrm{kWh}$ com o sistema operando apenas 8 horas diárias e 22 dias por mês. Em um ano, a redução de consumo totalizaria $192012 \mathrm{kWh}$, o que corresponde a aproximadamente 1.8 meses de produção.

Assim, recomenda-se que este procedimento seja executado toda vez que a condição operacional do sistema frigorífico necessite ser alterada, seja por imposição da produção ou por condição climática em função da grande variação experimentada nas diferentes estações climáticas no estado do Rio Grande do Sul. Como Alternativa, sugere-se a implementação de um sistema inteligente para acionamento dos motores com condições variáveis em função da performance da planta.

Agradecimentos: Os autores agradecem ao Armazém Frigorífico pela disponibilização de sua planta para execução do trabalho, ao IFRS e à FURG pelo apoio às atividades de pesquisa, bem como à Empresa Less Energy pelo apoio técnico.

\section{Referências}

1. ACUNHA JR, I. et al. Geração de entropia durante a compressão em sistemas de refrigeração por NH3. VI CBTermo, 2011

2. AL-BASSAM, E.; ALASSERI, R. Measurable energy savings of installing frequency drives for cooling towers' fans, compared to dual speed motors. Energy and Buildings, v. 67, p. 261-266, 2013.

3. ASHRAE. Handbook HVAC Systems and Equipament. 2000

4. BEJAN, A.; TSATSARONIS, G.; MORANM M. Thermal Design e Optimization. 1a ed, New York, John Wilwy \& Sons Inc, 1996.

5. CHATO, J. Laminar condensation inside horizontal and inclined tubes. Journal ASHARE, v. 4, p. 52-60, 1962

6. ÇENGEL, Y.; GHALAR, A. Transferência de Calor e Massa: uma abordagem prática. 4a ed., Porto Alegre, AMGH, 2012

7. MCQUISTON, D.; Faye, C. Heating, Ventilating and Air Conditioning: analysis and design. 4a ed., New York, Wiley, 1994.

8. MOBLEY, R. Plant Engineer's Handbook, Butterworth, 2001.

9. PARKER, O.; TREYBAL, E. The heat, mass transfer characteristics of evaporative coolers. Chemical Engineering Progress Syposium Series, v. 57, p. 138-149, 1961.

10. PENG, Q.; DU, Q. Performance evaluation of a variable frequency heat pump air conditioning system for electric bus. International Journal of Fluid Machinery and Systems, v. 8, p. 13-22, 2015.

11. PLESSIS, G.; LIEBENBERG, L.; MATHEWS, E. The use of variable speed frives for cost-effective energy savings in south african mine cooling systems. Applied Energy, v. 111, p. 16-27, 2013.

12. QURESHI, T.; TASSOU, S. Variable-speed control in refrigeration systems. Applied Thermal Engineering, v. 16(2), p. 103-113, 1996.

13. STOECKER, F.; JABARDO, S. Refrigeração Industrial. 2a Ed, São Paulo, Edgar Blucher, 2004.

14. YU, F.; CHAN, K. Modeling of the coefficient or performance of an air-cooled screw chiller with variable speed condenser fans. Building and Environment,v. 41, p. 407-417, 2006. 